\title{
Discussion on the Teaching Reform of Civil Engineering Mechanics Based on the Difference of Students
}

\author{
Wenting QU*, Hongfei XU \\ Civil Engineering and Architecture Institute \\ Zaozhuang University \\ Zaozhuang, China \\ *Corresponding author
}

\begin{abstract}
Engineering mechanics is an important basic course for civil engineering major, and its teaching effect directly affects students ' professional level and career development. Due to the differences in student sources, different students have different mechanical foundations, so the adoption of unified teaching mode cannot guarantee the learning effect of all kinds of students. How to teach students according to their aptitude and reform the teaching mode of engineering mechanics are discussed in this paper. It is proposed that different programs, different teaching methods and different assessment methods were adopted for different students. These reforms have achieved certain results in teaching practice and pointed out feasible directions for the teaching reform of engineering mechanics.
\end{abstract}

Keywords-engineering mechanics; different sources of students; reform; teaching program; evaluation mode

\section{INTRODUCTION}

Mechanics courses are always basic courses of all kinds of engineering majors, and every engineering student should have certain mechanical accomplishment to become a qualified employee. For civil engineering majors, mechanical knowledge is closely related to engineering safety. As an important professional basic course, engineering mechanics is not only to cultivate students' logical thinking and mechanical accomplishment, but also to prepare for the subsequent study of professional courses. The teaching effect of engineering mechanics directly affects students' professional level and career development. Therefore, it is very important for civil engineering talent training to discuss how to improve the teaching effect of engineering mechanics.

Due to the characteristics of the subject, engineering mechanics course is difficult and demanding. Students often feel bored with the course content. So engineering mechanics has always been one of the courses with high failure rate. In recent years, college enrollment has varied greatly based on the need to provide various special talents for the construction industry. For example, in Zaozhuang University where the author works, there are three sources of students in civil engineering. The three sources respectively are students enrolled in the general college entrance examination, students enrolled in the spring college entrance examination, and students who have been upgraded. In the teaching practice, it is found that students from different sources have great differences in the basis of mechanics, and their employment trends are also quite different, which brings great challenges to the teaching practice of engineering mechanics. If the uniform large class teaching is adopted, it is difficult to coordinate the teaching content and teaching schedule due to the differences of students' receptivity and employment trend. Those who have a good foundation feel it is a waste of time, while those who have a poor foundation may abandon themselves; Those who want to take part in the postgraduate entrance examination or want to engage in the design work have higher requirements on the knowledge depth, while those who want to engage in the construction are not interested in the deeper mechanical knowledge. Finally, all kinds of students are not satisfied in the uniform large class teaching. The fact proves that the traditional unified program and unified examination mode can not guarantee the good teaching effect, so it is very necessary to adopt different teaching methods for different students. In this context, the author has carried out the engineering mechanics teaching reform based on the differences of students in the teaching practice over the years, and has achieved certain results.

\section{TEACHING Reform BASED ON The DifFERENCES OF STUDENTS}

At present, there are three sources of students in civil engineering. The three sources respectively are students enrolled in the general college entrance examination, students enrolled in the spring college entrance examination, and students who have been upgraded. These three types of students differ greatly in their mechanical foundation and development trend.

Compared with the other two types of students, the students enrolled in the ordinary college entrance examination have a good foundation in mathematics and mechanics, and have a strong ability to accept lessons. Most of these type students choose to be admitted to graduate school after graduation, so they have a high demand for mechanical knowledge. Therefore, they have less resistance and less difficulty in learning. 
As mechanics is a compulsory subject in the entrance examination for civil engineering majors, students who have passed the spring college entrance examination and who have been upgraded have already received certain mechanical training before entering the university and have a certain basic knowledge of mechanics. However, it is found in teaching that the mechanical foundation of these two types of students is relatively weak and their ability to accept knowledge is obviously poor. Through investigation, it is found that the degree of mechanical training before the entrance of students is extremely shallow. Most students only received short-term targeted practice through some training institutions, and they knew nothing about the reason. They can do simple questions, but they do not understand the principles. Students just mechanically accepted some kind of stylized solving method, but they do not form mechanical thinking and will not think independently. These two kinds of students have obvious difficulties in the study of engineering mechanics. On one hand, it is difficult for them to understand the new teaching content due to the poor foundation of mathematics and mechanics; On the other hand, the inherent thinking formed in pre-school training is difficult to break so the students have difficulty in understanding principles and so on. Moreover, some students tend to engage in the construction work rather than the design work after graduation. So they don't pay much attention to the course of mechanics and have serious resistance to it. Under this background, traditional teaching methods are difficult to achieve good results.

It is necessary to teach students according to their aptitude due to the different sources of students. The author has carried on the following reform and exploration through many years engineering mechanics teaching practice.

\section{A. Break Unified Outline and Reform Teaching Content}

The general engineering mechanics teaching material is rich in content and covers a wide range of knowledge. It is impossible to achieve all the content in the limited class time. Therefore the content and range should be chose in the teaching. When developing the teaching program, the acceptance ability of students from different sources and the demand degree of different employment directions should be taken into account in particular, so that the program will be truly in line with the characteristics of students, so as to be specific and distinctive, instead of using the traditional unified program to require different students.

Engineering mechanics includes two parts of theoretical mechanics and material mechanics. Theoretical mechanics is divided into three parts: statics, kinematics and dynamics, while the main content of material mechanics is the calculation of stress and deformation of various kinds of bars. In the current theoretical teaching, due to the limitation of the class time and considering the needs of civil engineering specialty, the theoretical mechanics part only focuses on statics, while kinematics and dynamics knowledge are not used as teaching contents.

The teaching content is also different for different students. Students enrolled in the general college entrance examination have a good foundation in mathematics and mechanics. For these students, considering the requirements of design work or postgraduate entrance examination in the future, most knowledge of statics and material mechanics is required to be mastered. For students enrolled in the spring college entrance examination and students who have been upgraded, due to the weak foundation of mechanics and the lack of students taking part in the postgraduate entrance examination, only the most basic knowledge is involved in the teaching content. For example, the static part focuses on the plane force system, while the spatial force system is less involved. The knowledge of stress and strain state analysis and strength theory, which are more difficult in the part of material mechanics, is also less involved. The author thinks that it is more meaningful to let students grasp a small part of knowledge within their ability range than to impart more knowledge with nothing absorbed. Students enrolled in the spring college entrance examination and students who have been upgraded are highly required in experimental teaching, which is due to high practical ability requirement of their employment directions. In the reform of the traditional experimental project, teachers no longer arranged the preparatory work before the experiment, but formed the group of students to prepare the experiment and set the experiment steps independently. In addition to experiments, students can also make simple mechanical models to assist learning.

\section{B. Adopt Small-class Teaching and Reform Teaching Methods}

The course of engineering mechanics has certain difficulty and needs a lot of practice to achieve good teaching effect. The large class teaching mode cannot guarantee the teaching effect and does not meet the requirement of teaching students according to their aptitude. Therefore, students from different sources should be trained in small classes and taught separately. In addition to the content difference of the teaching, the teaching method is also different.

The mechanics teaching for students enrolled in ordinary college entrance examinations pays more attention to the explanation and derivation of the principle. The aim is to cultivate students' mechanical thinking and to enable students to draw inferences. The students should be inspired to think independently most of the time with proper practice in class. Heuristic teaching is often adopted to pay attention to the connection between the front and the back of this course and its connection with other courses, so as to guide students to summarize and comprehensively apply the knowledge. The speed of teaching can be appropriately fast. In addition, more comprehensive design experiments should be set up in experimental teaching.

For students enrolled in the spring college entrance examination and students who have been upgraded, special attention should be paid to speed and depth control in teaching. For example, the multimedia animation can be used to help students understand, but the use of multimedia can easily lead to fast teaching so that the students can not keep up with the progress. Therefore, in the use of the teaching means teachers should also pay attention to cooperating with the blackboard to explain the principles clearly and to control the speed of teaching [1].There should be a lot of exercises for each type of question in the class. In addition, from the 
perspective of employment needs of these two types of students, special attention should be paid to practical case teaching [2].In the course of engineering mechanics, attention should be paid to illustrating some important mechanical phenomena or structures by following the civil engineering examples or life examples familiar to students, so as to improve students' interest in learning. The actual cases, especially the cases of this major, are interesting and readily accepted by students. The actual case explanation is closely related to some key knowledge points, which is easy to achieve a good teaching effect [3].

\section{Break Test-only and Reform Assessment Methods}

The course of engineering mechanics is highly theoretical, and the traditional assessment method is mainly based on students' written test scores [4]. However, the examination-only assessment method is relatively single and does not adapt to the difference of students [5].In the teaching of engineering mechanics; the author adopts different assessment methods for different students.

For students enrolled in ordinary college entrance examinations, written test scores account for $70 \%$ of the proportion and the usual classroom attendance and practice account for $30 \%$. Students need to perform well in the examination to achieve good results, which requires a higher level of mechanics for such students.

For students enrolled in the spring college entrance examination and students who have been upgraded, considering that only a small number of them will be engaged in design work or the postgraduate entrance examination, these two types of students only need to have basic mechanical concepts and mechanical literacy. Therefore, the proportion of written test scores was reduced to $60 \%$, but a large number of exercises and recitation classes should be added at ordinary times and the mid-term exam should be set to increase the average score to $40 \%$. Because of much usual practice, as long as the students performed well in ordinary practices, it represented that the students have already achieved certain mechanical accomplishment and they can also pass the course even if the examination performance was bad.

\section{REFORM EFFECT}

Through years of practice and adjustment, the above reforms have achieved certain results. In practice, it is found that ability, interest and the hope to achieve the goal are the decisive factors influencing students' learning effect and the three aspects affect each other. Blindly increasing the content and depth of teaching cannot achieve good teaching results, and it is extremely necessary to design teaching programs according to the characteristics of different students [6]. Under the original unified teaching mode of large classes, students' receptivity and learning interest are greatly different due to differences in their foundation and employment demands, and the course progress is difficult to be coordinated. Some students fail to keep up with the progress, so the failure rate is higher. After changing to small-class teaching, the content, teaching method and assessment method of different students were adjusted accordingly, so that the content and difficulty of teaching were in line with the accepting ability of corresponding students, and the assessment method was also in line with the characteristics and demands of different students. Therefore, students' learning interest has been improved. The students can respond to the assessment according to their own characteristics, and the pass rate has been greatly improved.

\section{CONCLUSIONS}

The engineering mechanics course occupies a very important position in the civil engineering major and is the important foundation for the follow-up courses [7]. It is very important for students to lay a good foundation of mechanics. The teaching of engineering mechanics should not be monotonous, but should be designed according to different students' characteristics and employment demands [8]. Based on the characteristics of different students, the author adopts the targeted teaching outline, teaching method and examination method to adapt to the abilities and demands of all kinds of students in teaching practice, which improves students' interest and enthusiasm in learning and improves the teaching effect. It can be seen that the direction of reform is right and the reform is effective.

It should be noted that the teaching reform of engineering mechanics is by no means only a trial or two, but a long-term trial and adjustment, which should be adjusted at any time according to the characteristics of different students and the development of the industry [9]. Although the existing reform methods have achieved some results, there are some problems. The outstanding problem is that the teaching design based solely on the source of students can only meet the requirements of the majority of students, but can not adapt to the particularity of individual students. For example, if the students who have been upgraded want to take part in the postgraduate entrance exam which has higher requirements on the knowledge of mechanics, the teaching of mechanics for these students is obviously insufficient. In the future, it should be considered to adjust the teaching methods according to students'independent choices.

\section{REFERENCE}

[1] J.X. Wang and Y.T. Ge, "Teaching practice of engineering mechanics course on multimedia and blackboard writing combination," Experiment Science and Technology, Vol. 16, pp. 57-60, 2018.(In Chinese)

[2] Y.Q. Gu, H.Y. Jia and L.Y. Su, "Reform of engineering mechanics course teaching based on engineering education professional certification,” Higher Education, Vol. 2, pp. 172-173, 2018.(In Chinese)

[3] M. Zhang, H.H. Huang and SH. Chen, "Teaching method and practice reform of engineering mechanics based on civil engineering training," Education Teaching Forum, Vol. 26, pp. 124-125, 2016.(In Chinese)

[4] C.H. Guo, "Some thoughts on the reform of engineering mechanics teaching,” Education Exploration, Vol. 2 ,pp. 31-32, 2013.(In Chinese)

[5] F. Yu, "Teaching practice of engineering mechanics in independent college based on the principle of teaching students according to their aptitude," Educational Research and Experiment, Vol. 8, pp. 7-9, 2009.(In Chinese)

[6] J.S. Fang and Z.Z. Wang, "Mechanical course teaching reform under the background of graduate engineer cultivation," Journal of Technology College Education, Vol. 29, pp. 125-127, 2010.(In Chinese) 
[7] Y.M. Yang, "Research and practice of engineering mechanics course reform in colleges and universities," Journal of ChongQing university of science and technology, Vol. 2, pp. 185-186, 2013.(In Chinese)

8] Z.X. Xie and T.P. Qiu, “The exploration of transforming engineering mechanics teaching method," Mechanics And Practice, Vol. 22, pp. 55-57, 2000.(In Chinese)
[9] Y. Du, H.B. Liu and H.G. Gao, "Discussion on the teaching reform of civil engineering mechanics," Science and Technology Innovation Herald, Vol. 16, pp. 214, 2008.(In Chinese) 